\title{
Funnel-shaped retrieval device for wrapping large colorectal resection specimens
}

Endoscopic submucosal dissection (ESD) has facilitated en bloc resection of large colorectal tumors [1]. The retrieval of a moderately sized specimen after ESD is common with use of a net forceps [2]. It is difficult however to retrieve a large colorectal specimen without any damage because of the typical anatomy of the anal canal with its narrow lumen, which sometimes results in the failure of accurate pathological evaluation. Although several retrieval methods have been reported recently, they seem to be insufficient in terms of wrapping the whole of a large specimen $[3,4]$. Here we introduce a novel procedure that is reliable for the retrieval of a large colorectal specimen.

A 51-year-old man presented with a 40-mm laterally spreading tumor located in the cecum. The retrieval method using a net forceps via the anal canal might have damaged the en bloc specimen after complete ESD. Therefore, we developed a new retrieval method using an overtube (Top Corporation, Tokyo, Japan) and a piece of waterproof cloth from an operating gown (Hopes isolation gown JIG-01B: Japan Medical Products, Hokkaido, Japan). After informed consent had been obtained from the patient, the following strategy was designed.

First, the en bloc ESD specimen was carried from the cecum to the lower rectum using grasping forceps. Next, a fanshaped waterproof cloth was hand-made and this was attached to an overtube in a funnel-shaped manner (\$Fig.1). After inserting the overtube into the lower rectum, the large specimen was wrapped in the cloth using the grasping forceps that had been inserted through the endoscope channel ( Fig.2). Finally, the endoscope and the overtube were taken out together from the anal canal ( $\vee$ Fig. 3 ; $\triangleright$ Video 1$)$. The resected specimen $(50 \times 45 \mathrm{~mm}$ in diameter) was completely retrieved without any damage or complications ( Fig.4).
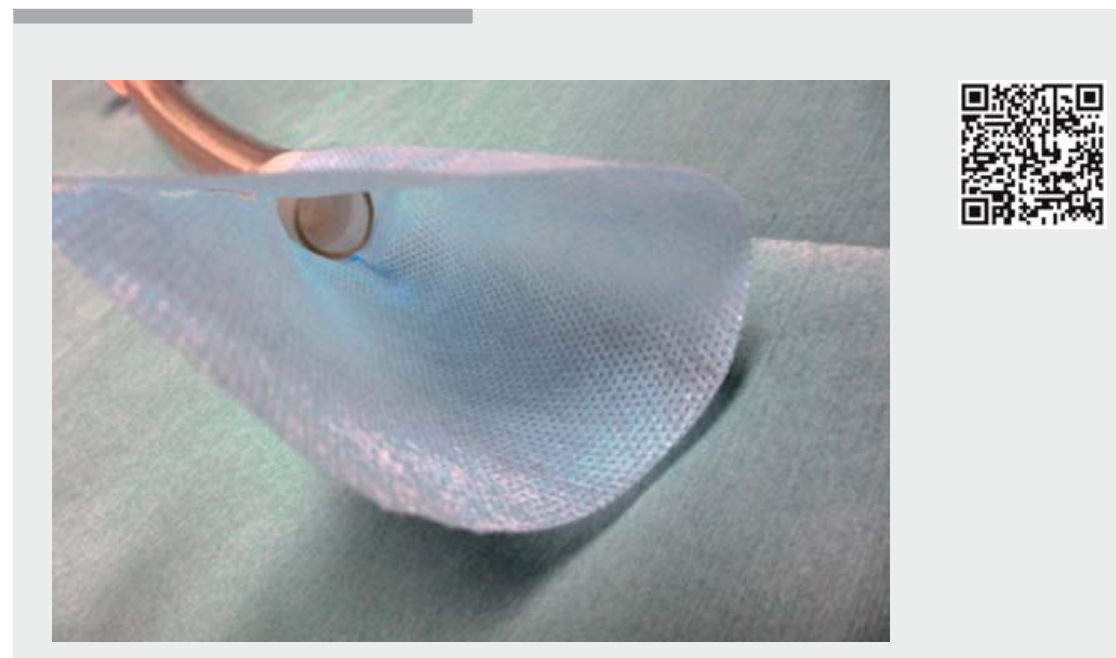

Video 1 The novel retrieval device that can be wrapped around a large colorectal resection specimen is produced using an overtube and a waterproof cloth that is hand-made in a funnel-shaped manner. The specimen is completely retrieved without any damage.
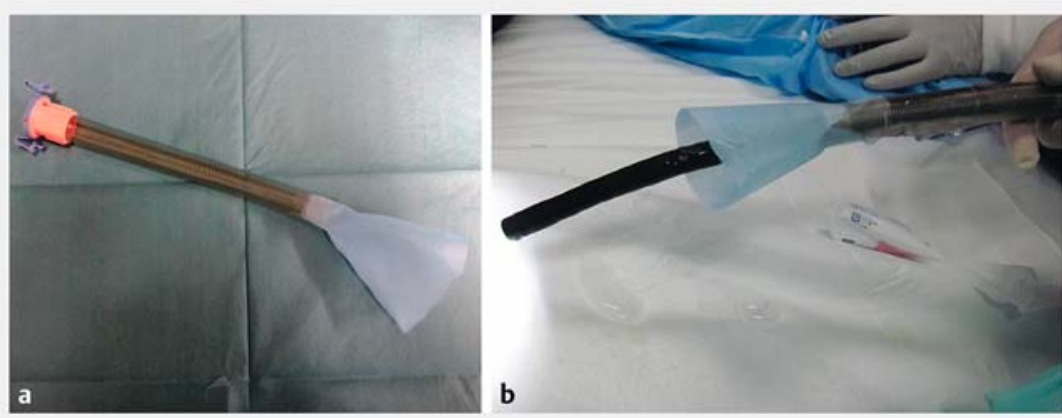

- Fig. 1 Photographs showing: a the retrieval equipment, which consisted of an overtube and a waterproof cloth that had been attached in a funnel-shaped manner; $\mathbf{b}$ the endoscope being passed smoothly through the funnel-shaped retrieval device.

This innovative method using a particular cloth, which has several functions including water repellency and shape memory, may be suitable for the retrieval of large colorectal specimens.

Endoscopy_UCTN_Code_TTT_1AQ_2AD

\section{Competing interests}

None 

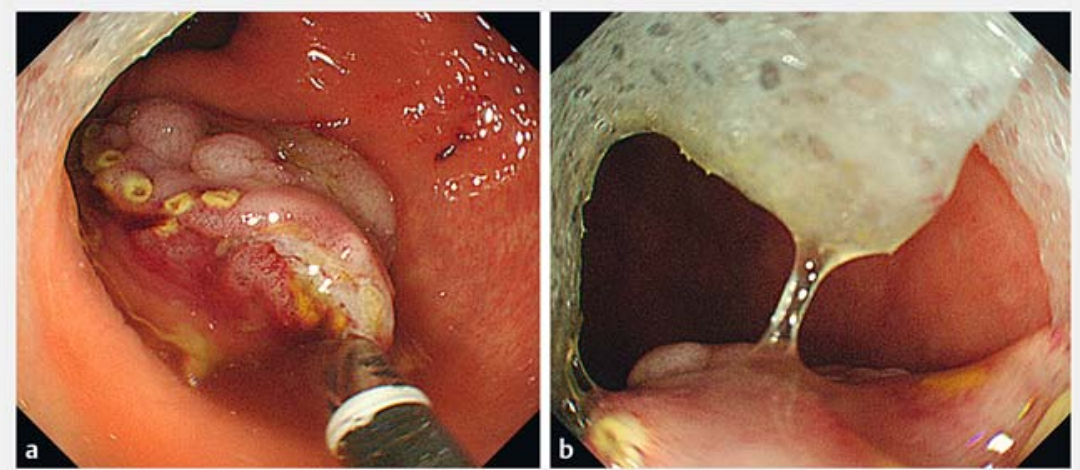

- Fig. 2 Endoscopic images showing: a the en bloc endoscopic submucosal dissection specimen that had been carried from the cecum to the rectum using grasping forceps; $\mathbf{b}$ the specimen being pulled into and wrapped within the funnel-shaped cloth using the grasping forceps.

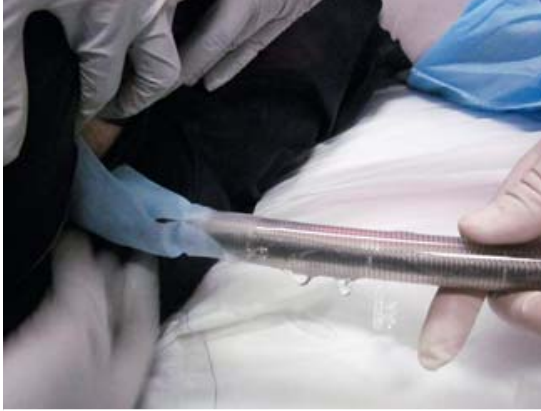

Fig. 3 The endoscope and the overtube with the attached cloth were taken out together, allowing the specimen to be completely retrieved without any damage

The Authors

Nobuya Kobayashi, Hirohito Mori, Hideki Kobara, Noriko Nishiyama, Shintaro Fujihara, Tatsuo Yachida, Tsutomu Masaki

Department of Gastroenterology and Neurology, Faculty of Medicine, Kagawa University, Kagawa, Japan

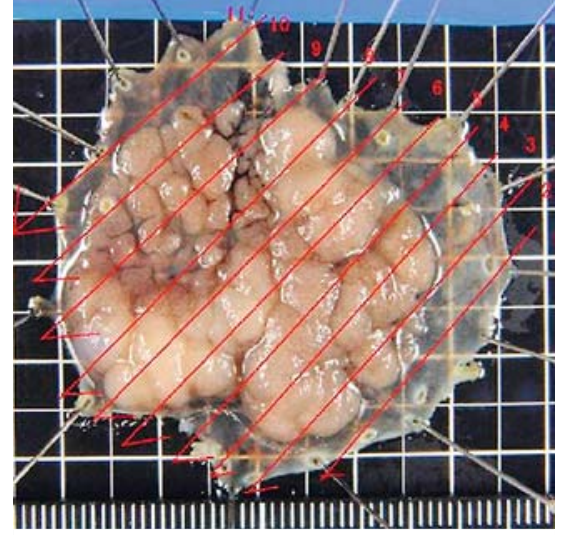

- Fig. 4 Macroscopic appearance of the retrieved specimen, which was $50 \times 45 \mathrm{~mm}$ in size.

Corresponding author

\section{Hideki Kobara, MD, PhD}

Department of Gastroenterology and Neurology, Faculty of Medicine, Kagawa University, 1750-1 Ikenobe, Miki, Kita, Kagawa 761-0793, Japan

Fax: +81-87-8912158

kobara@med.kagawa-u.ac.jp

\section{References}

[1] Saito Y, Uraoka T, Matsuda T et al. Endoscopic treatment of large superficial colorectal tumors: a case series of 200 endoscopic submucosal dissections (with video). Gastrointest Endosc 2007; 66: 966 - 973

[2] Miller K, Waye JD. Polyp retrieval after colonoscopic polypectomy: Use of the Roth Retrieval Net. Gastrointest Endosc 2001; 54 : 505-507

[3] Fukita Y, Takeda T, Toyomizu M et al. A novel retrieval method using a Cusco speculum for large colorectal resection specimens following endoscopic treatment. Endoscopy 2016; 48: E336-E337

[4] Tanaka S, Toyonaga T, East J et al. Endoscopic retrieval method using a small gripseal plastic bag for large colorectal resection specimens after endoscopic submucosal dissection. Endoscopy 2010; 42: E186E187

\section{Bibliography}

DOI https://doi.org/10.1055/s-0043-113550

Published online: 29.6.2017

Endoscopy 2017; 49: E217-E218

(c) Georg Thieme Verlag KG

Stuttgart · New York

ISSN 0013-726X

\section{ENDOSCOPY E-VIDEOS}

https://eref.thieme.de/e-videos

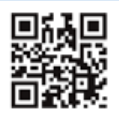

Endoscopy E-Videos is a free access online section, reporting on interesting cases and new techniques in gastroenterological endoscopy. All papers include a high quality video and all contributions are freely accessible online.

This section has its own submission website at

https://mc.manuscriptcentral.com/e-videos 